\title{
Association between disease-related malnutrition and innate immunity gene expression in critically ill patients at intensive care unit admission
}

\author{
ROBERT SŁOTWINSSKI I ALEKSANDRA DAZBROWSKA ${ }^{1}$, KATARZYNA KOSAEKA ${ }^{2}$, \\ ANDRZEJ KAŃSKI ${ }^{3}$, SYLWIA MAEGORZATA SEOTWIŃSKA \\ ${ }^{1}$ Department of Immunology, Biochemistry, and Nutrition, Medical University of Warsaw, Poland \\ ${ }^{2}$ Central Clinical Hospital of the Ministry of Interior and Administration, Warsaw, Poland \\ ${ }^{3} 2^{\text {nd }}$ Department of Anaesthesiology and Intensive Care, Medical University of Warsaw, Poland \\ ${ }^{4}$ Department of Oral Hygiene, Medical University of Warsaw, Poland
}

\begin{abstract}
The aim of the study was to analyse the relationship between nutritional disorders and the expression of innate antibacterial response genes in patients admitted to the intensive care unit (ICU). In 46 patients with severe malnutrition and life-threatening surgical complications, nutritional status tests were performed on the basis of the NRS 2002 (Nutritional Risk Screening) scale, cytokine, albumin, $C$-reactive protein concentrations, anthropometric tests, and body composition analysis. Concurrently, the expression of Toll-like receptor 2, NOD1, TRAF6, and HMGB1 genes was determined in peripheral blood leukocytes at the mRNA level using real-time polymerase chain reaction. It was found that both the nutritional status and the gene expression changed depending on the group of patients studied (including the group of survivors vs. non-survivors). Significant correlations were found between the results of routine tests used in the diagnostics of malnutrition (including NRS 2002, resistance, reactance, phase angle, excess of extracellular water) and the expression of the studied genes. Moreover, the expression of TRAF6 and HMGB1 genes correlated with the Acute Physiology and Chronic Health Evaluation II scale and the age of the patients. The results of the research suggest that the expression of innate antibacterial response genes may be a new diagnostic tool complementing the assessment of nutritional disorders in surgical patients admitted to the ICU. These tests may be helpful in providing more accurate diagnostics of the genetic effects of malnutrition and in the monitoring of patients for whom nutritional treatment is planned to support the functions of the immune system, thereby increasing the effectiveness of this type of treatment in the ICU.
\end{abstract}

Key words: malnutrition, gene expression, innate immunity.

(Centr Eur J Immunol 2020; 45 (4): 414-424)

\section{Introduction}

Despite tremendous advances in the therapy of critical illness, mortality in intensive care units (ICU) is still high, especially in the growing elderly population with sepsis and septic shock [1-4]. Among the many factors affecting the increase in ICU mortality, nutritional disorders of the patients and impaired immunity have a basic significance [5-9]. Both of these factors significantly increase the number of severe complications and organ failures, which are the most common causes of ICU deaths [10]. In addition to the underlying disease, such as cancer, trauma, or sepsis, malnutrition intensifies ongoing immunity disorders and requires early identification and appropriate nutritional support. Malnutrition, which worsens with increasing length of treatment, is an independent risk factor common to the entire group of critically ill patients treated in the ICU. The risk of malnutrition is a considerable burden affecting up to $78 \%$ of patients treated in the ICU, and malnutrition at ICU admission is predictive of further adverse outcomes [11, 12]. Nutrition status disorders have been most commonly reported in critically ill patients with sepsis and persistent inflammation and immune suppression catabolism syndrome (PICS) treated for extended periods in ICUs or surgery units [13-15]. In these patients deple-

Correspondence: Robert Słotwiński, Department of Immunology, Biochemistry and Nutrition, Medical University of Warsaw, 3 Oczki St., 02-007 Warsaw, Poland, e-mail: robert_slotwinski@yahoo.com Submitted: 14.09.2020; Accepted: 5.10.2020 
tion of nutrients, persistent inflammation, and immunosuppression lead to severe complications such as impaired wound healing after major surgery, leakage of intra-abdominal anastomoses, sepsis, and multiple organ failure (MOF).

Unfortunately, in a majority of malnourished patients treated in the ICU, improvement of nutrition status and immunity by using enteral or parenteral nutrition (including immunonutrition) in a short time is impossible, due to the significant dynamics of disease progression including accumulating complications, time-dependent increases in gut permeability, and bacterial challenge. The biggest problem with nutritional treatment relates to critically ill patients with septic shock and MOF, requiring primarily resuscitative therapy in which standard enteral nutrition and immunonutrition should be withheld until the patient is fully resuscitated and/or stable. Otherwise, aggressive nutrition therapy containing high concentrations of immunologically active substances (e.g. glutamine, arginine, lipid emulsions) will worsen treatment results and even increase mortality [16-21]. The Surviving Sepsis Campaign also recommends early initiation of enteral nutrition in patients who can be fed, and intravenous glucose with advanced enteral feeds (e.g. increases in enteral diet infusion of $25 \mathrm{ml} / \mathrm{h}$ every $4-8 \mathrm{~h}$ for gastric tubes or 6-12 $\mathrm{h}$ for duodenal tubes) as tolerated for patients in whom enteral feeding is not feasible over the first seven days [22]. In these patients, progressive catabolism effectively prevents rapid correction of growing protein-energy deficiencies by enteral or parenteral nutrition, which increases the severity of immunosuppression and the risk of further complications that increase mortality. Considering the above, it can be assumed that a better understanding of the relationship between nutritional status changes and immunity disorders is crucial for improving treatment outcomes in critically ill patients.

Another important and still insufficiently understood mechanism in the heterogeneous group of critically ill patients from ICUs, with disease-related malnutrition and various severe complications, is connected with the parallel changes in the expression of genes encoding signalling pathway proteins of the innate antibacterial response, which is the first line of defence against pathogens. Controlled improvement of immunity (especially inflammatory response) by altering the expression of these genes with appropriate nutritional therapy is a new and promising research direction. Innate immune cells (i.e. neutrophils, monocytes/macrophages, dendritic cells, NK cells) initially recognise and are activated by pathogen-associated molecular patterns or endogenous alarmins called damage-associated molecular patterns, otherwise known as 'danger signals', released by damaged cells, injured tissues, and necrotic cells (e.g. high-mobility group protein B1-HMGB1) [23]. The initial sensing of infection is mediated by innate pattern recognition receptors (PRRs), which include, but are not limited to, Toll-like and NODlike receptors [24]. Toll-like receptors (TLRs), depending on the location (cell membrane or endosomal membranes), bind lipids, proteins, or nucleic acids and transmit signals through adaptor proteins to the nucleus, leading to regulation of the innate and adaptive immune response. Toll-like receptors are crucial receptors for the initiation of the inflammatory response during sepsis [25, 26]. Activation of TLR signalling by bacterial components leads to acute inflammation, culminating in septic shock in some cases. As previous studies have shown, among all TLRs, TLR2 and TLR4 are the two most notable contributors to the pathogenesis of sepsis [27, 28]. It can be assumed that the modulation of expression of TLRs, which bind bacterial antigens and are also present in the cells of the intestinal mucous membrane, neutrophils, monocytes, and dendritic cells as well as the modulation of expression of signalling pathway proteins in those cells by early administration of new enteral nutrition support formula, can help to efficiently eliminate microorganisms, reduce the inflammatory response, and deter immunosuppression [9, 29-31]. This concept is particularly important in view of the increasing resistance of microorganisms to antibiotics, immuno-compromised critically ill patients with severe malnutrition, and the dysfunction of gut-associated lymphoid tissue (GALT) with extraordinary body surface area containing a high density of lymphatic tissues and immune cells, as well as the low effectiveness of the existing nutritional treatment methods in this group of patients.

Experimental studies have shown that enteral treatment with glutamine was associated with down-regulation of TLR4, myeloid differentiation factor 88 (MyD88), TRAF6 mRNA (TNF receptor-associated factor 6) expression, and decreased intestinal mucosal injury caused by lipopolysaccharide endotoxaemia in rats [32]. Glutamine induced downregulation of TLR4 expression in intestinal epithelial cells infected with gram-negative bacteria [33]. In malnourished patients with pancreatic cancer, glutamine abolishes the high expression level of the TLR 4 gene in leukocytes before major surgery [34]. Studies on TLR receptor inhibition and TLR agonists have highlighted the potential for pharmacological regulation of multiple TLR signalling pathways as a promising therapeutic strategy to control excessive inflammation and recruitment of innate leukocytes to the site of infection [35-37]. Thus, both nutritional treatment and antibody therapy can advantageously modulate gene expression of the innate antimicrobial response.

Our objective was to analyse the relationship between nutritional status disorders, and changes in the expression of genes encoding the signalling pathway proteins of innate antibacterial response (TLR2, NOD1, TRAF6, and HMGB1) examined at the mRNA level in peripheral blood leukocytes of critically ill patients at ICU admission. A more thorough understanding of this relationship is an 
attempt to supplement the diagnosis of nutritional status disorders in ICU surgical patients with simple genetic tests, which may be helpful in patients monitoring and increasing the effectiveness of nutritional treatment modulating the expression of genes of the innate antibacterial response. The selection of parameters evaluating the nutritional status and gene expressions was based on the results of our previous studies conducted on malnourished patients treated in the ICU and on the surgical ward [38-40].

\section{Material and methods}

Forty-six patients ( 22 women and 24 men, median age 60.5 , range $23-87$ years) admitted to the ICU were investigated in a prospective manner. Patients were transferred to the ICU from surgical departments because of life-threatening septic complications after major abdominal surgery or reoperations due to complications associated with severe acute pancreatitis, biliary tract surgery, or colon and pancreas tumour resections. Complications mainly included gastrointestinal perforations, anastomotic leakage, intraabdominal abscesses with sepsis, septic shock, and respiratory failure, and infections for other reasons like respiratory and urinary tract septic infections. Thirty patients $(65 \%)$ in this group required a respirator and 15 (32.6\%) with an Acute Physiology and Chronic Health Evaluation II (APACHE II) median score of 26 (range 11-48) died within the first 7 days of treatment as a result of MOF. In the entire study group, the severity-of-disease and the risk of death on the APACHE II score was 25 (range 11-48), and in survivors 25 (range 11-43). Severe malnutrition was found in all patients (Nutritional Risk Screening - NRS 2002, score $\geq 3$ ).

The study protocol excluded patients with uncontrolled bleeding, burns, pregnancy, or terminal illness, patients after chemo- or radiotherapy, patients with advanced cancer disease, chronic liver and kidney disease, diabetes type I, and chronic steroid therapy before admission to the ward, and patients after limb amputations, with metallic prostheses and pacemakers. The control group consisted of 30 healthy adult volunteers without signs of inflammatory disease, matched for gender and age, with normal nutritional status.

Clinical monitoring of patients included observation of the early results of treatment (including mortality rate), the routine evaluation of severity-of-disease, and the risk of death according to the APACHE II score, performed by the anaesthesiologist at admission to the ICU, as well as a nutritional status assessment carried out by a dietitian within 48 hours of admission to the ward, including NRS 2002 score, anthropometry, and bioelectrical impedance (BI) analysis. The nutritional status assessment also included laboratory parameters measured at admission, such as albumin, C-reactive protein, and cytokine (IL-6, TNF- $\alpha$ ) concentrations in peripheral blood (Table 1). The Nutritional risk screening consists of a nutritional score with identification of patients at risk (score $\geq 3$ is severe malnutrition), a high risk of occurrence of malnutrition - related complications (scoring $\geq 5$ ), a severity of disease score, and an age-adjustment for patients aged $>70$ years $(+1)$, as previously described [41, 42]. Impedance data were obtained using a multi-frequency bioimpedance analyser (MF-BIA) model BioScan 920-2 (Maltron Int., UK). In BI analysis, the resistance $(\mathrm{R})$ and reactance $(\mathrm{Xc})$ values, the phase angle (PhA), and the following body composition parameters were calculated: body cell mass (BCM), muscle mass (MM), fat mass (FM), fat-free mass (FFM), total body water (TBW), extracellular water (ECW), excess of extracellular water (ExECW), and intracellular water (ICW). All measurements were taken on admission to the ICU.

The diagnosis of severe infection cases with symptoms of systemic inflammatory response syndrome, sepsis, severe sepsis, and septic shock was based on the classic clinical criteria adopted by the American College of Chest Physicians/Society of Critical Care Medicine (ACCP/SCCM), the Polish Working Group for Sepsis, and the Polish Society of Interdisciplinary Intensive Therapy and the Third International Consensus Definitions for Sepsis and Septic Shock (Sepsis-3) [43-46].

\section{Cytokine measurement}

The analysis of cytokine concentrations in peripheral blood plasma was performed on the basis of commercially available kits for enzyme-linked immunosorbent assay enzymatic immunoassay, in accordance with the instructions provided by the manufacturer (Quantikine Immunoassay human TNF- $\alpha$ and human IL-6, R \& D Systems Europe, Minneapolis, USA). Plasma was obtained from venous blood collected on heparin at admission to the ICU. Blood samples were centrifuged (2000 rpm for 30 minutes), plasma was isolated, and then frozen/stored at a temperature of $-70^{\circ} \mathrm{C}$ for further use. The lower limit of assay sensitivity was $0.5 \mathrm{pg} / \mathrm{ml}$ for TNF- $\alpha$, and $0.70 \mathrm{pg} / \mathrm{ml}$ for IL-6. Results are presented as medians in $\mathrm{pg} / \mathrm{ml}$. According to the results in the control group, the assumed normal level for IL-6 was $8.73 \mathrm{pg} / \mathrm{ml}$ (range of 0.79-31.53) and $4.72 \mathrm{pg} / \mathrm{ml}$ (range of 3.86-14.39) for TNF- $\alpha$.

\section{Sample collection and leukocyte isolation}

Blood samples were obtained from peripheral vein of patients at admission to the wards and from healthy volunteers as a control. Leukocytes were isolated from $10 \mathrm{ml}$ of ethylenediaminetetraacetic acid blood using Polymorphorep (AXIS-SHIELD PoC AS, Oslo, Norway). Briefly, blood was layered over Polymorphorep and centrifuged at room temperature $(500 \mathrm{~g} / 35 \mathrm{~min})$. The resulting monoand polymorphonuclear leukocyte fractions were harvested, washed in PBS solution to remove plasma and anticoagulant residues, suspended in a suitable medium, and immediately frozen at $-70^{\circ} \mathrm{C}$ until used in further analysis. 


\section{RNA extraction and reverse transcription}

Total RNA was extracted from leukocytes using the Total RNA Mini Isolation Kit (A\&A Biotechnology, Poland) according to the manufacturer's instructions. Isolated RNA was evaluated qualitatively and quantitatively using a NanoDrop spectrophotometer (Thermo Fisher Scientific Inc., Waltham MA, USA). Then the first-strand cDNA was synthesised by using VerteKit, (Novazym, Poznań, Poland). Briefly, $5 \mu \mathrm{g}$ total RNA was incubated at $70^{\circ} \mathrm{C}$ for 5 minutes with oligo $(\mathrm{dT})_{15}$ primers. Afterwards, M-MLV buffer, dNTPs mix, and Malooney Murine Leukemia Virus reverse transcriptase were added and the mix was incubated at $37^{\circ} \mathrm{C}$ for 60 minutes. Reaction was terminated by 10 -minute incubation at $70^{\circ} \mathrm{C}$. The reverse transcription products were analysed again on a NanoDrop spectrophotometer.

\section{Real-time polymerase chain reaction}

Real-time polymerase chain reaction (RT-PCR) was performed using a LightCycler 1.5 Instrument and LightCycler ${ }^{\circledR}$ FastStart DNA Master SYBR Green I detection kit (Roche Applied Science, Basel, Switzerland Cat.
No. 12239264001 ) as per the manufacturer's protocol. The final $20 \mu \mathrm{l}$ RT-PCR reaction included $500 \mathrm{ng} / \mu \mathrm{l} \mathrm{RT}$ product, $2 \mu \mathrm{l}$ of primers, $0.8 \mu \mathrm{l} \mathrm{MgCl}$, and $2 \mu \mathrm{l}$ of LightCycler ${ }^{\circledR}$ FastStart DNA Master SYBR Green I. DNaseRNase-free distilled water was added to a total volume of $20 \mu \mathrm{l}$ per capillary. The reaction was run as follows: $95^{\circ} \mathrm{C}$ for $10 \mathrm{~min}$, followed by 50 denaturation cycles at $95^{\circ} \mathrm{C}$ for $15 \mathrm{~s}$, appropriate annealing temperature (Table 2) for $10 \mathrm{~s}$, and $72^{\circ} \mathrm{C}$ extension step for $15 \mathrm{~s}$. After $50 \mathrm{cy}-$ cles, a melting curve was generated by slowly increasing $\left(0.2^{\circ} \mathrm{C} / \mathrm{s}\right)$ the temperature from $70^{\circ} \mathrm{C}$ to $99^{\circ} \mathrm{C}$ and measuring fluorescence. In each assay, GAPDH mRNA as well as TLR2, NOD1, TRAF6, and HMGB1 mRNA were measured simultaneously under identical conditions. The primer sequences and annealing temperatures are summarised in Table 2.

The results were analysed using the double delta method, assuming that the expression of the gene in the treated groups is $2^{-\Delta \Delta \mathrm{Ct}}$, where $\Delta \Delta \mathrm{Ct}=[\mathrm{Ct}$ target gene $-\mathrm{Ct}$ $\mathrm{GAPDH}]$ is the treated sample, and [Ct target gene $-\mathrm{Ct}$ GAPDH] is the control sample [47]. Each experiment was carried out in triplicate using GAPDH as internal standard. This calculation formula shows the expression of the gene

Table 1. Nutritional status changes in critically ill patients admitted to the intensive care unit

\begin{tabular}{|c|c|c|c|c|}
\hline $\begin{array}{l}\text { Nutritional status } \\
\text { variables }\end{array}$ & $\begin{array}{c}\text { ICU patients } \\
\text { (median, min-max) } \\
n=46\end{array}$ & $\begin{array}{c}\text { Survivors } \\
\text { (median, min-max) } \\
n=31\end{array}$ & $\begin{array}{c}\text { Non-survivors } \\
\text { (median, min-max) } \\
n=15\end{array}$ & $p$-values \\
\hline NRS 2002 score & $5.0(3-7)$ & $4.0(3-7)$ & $6.0(6-7)$ & 0.0000 \\
\hline $\operatorname{PhA}(\mathrm{o})$ & $6.54(4.1-15.86)$ & $6.7(4.1-15.86)$ & $6.17(4.8-13.71)$ & NS \\
\hline $\mathrm{R}(\Omega)$ & $384.5(145-741)$ & $413(145-741)$ & $322(149-494)$ & 0.03 \\
\hline $\mathrm{Xc}(\Omega)$ & $44.55(20.5-129.9)$ & $49.7(20.5-129.9)$ & $35.0(24.2-106.2)$ & 0.01 \\
\hline BCM (kg) & $29.7(21.25-45.37)$ & $29.66(22.27-45.37)$ & $29.73(21.25-41.11)$ & NS \\
\hline $\mathrm{MM}(\mathrm{kg})$ & $25.61(15.59-39.55)$ & $25.64(17.09-39.55)$ & $24.24(15.5-35.47)$ & NS \\
\hline $\mathrm{FM}(\mathrm{kg})$ & $22.51(6.17-95.91)$ & $26.78(6.17-95.91)$ & $15.05(7.61-29.36)$ & 0.001 \\
\hline FFM (kg) & $54.83(40.43-83.54)$ & $54.65(40.43-83.54)$ & $55.85(41.56-78.79)$ & NS \\
\hline TBW (1) & $42.78(28.86-67.53)$ & $41.86(28.86-67.53)$ & $45.42(30.45-65.78)$ & NS \\
\hline $\mathrm{ECW}(1)$ & $21.56(12.72-37.59)$ & $20.85(12.72-35.86)$ & $24.4(15.44-37.59)$ & NS \\
\hline ExECW (1) & $2.61(0.00-5.0)$ & $1.79(0.00-5.0)$ & $5.0(0.00-5.0)$ & 0.04 \\
\hline ICW (1) & $21.63(15.01-33.83)$ & $21.66(15.23-33.83)$ & $21.61(15.01-28.94)$ & NS \\
\hline $\mathrm{BMI}=\mathrm{Wt}(\mathrm{kg}) / \mathrm{Ht}^{2}\left(\mathrm{~m}^{2}\right)$ & $27.6(19.2-60)$ & $29.55(19.8-60)$ & $26.7(19.02-31.4)$ & 0.01 \\
\hline $\mathrm{TSF}(\mathrm{mm})$ & $11.9(2.2-29)$ & $13.0(2.2-29)$ & $10.13(5.4-15.8)$ & 0.01 \\
\hline $\mathrm{MAC}(\mathrm{mm})$ & $25.20(17.8-33)$ & $25.7(17.8-33)$ & $24.3(19.7-30)$ & NS \\
\hline Albumin (g/dl) & $2.1(1.5-3.9)$ & $2.2(1.5-3.9)$ & $2.1(1.5-3.9)$ & NS \\
\hline CRP (mg/l) & $189.45(4.0-537.5)$ & $207.8(20.3-537.5)$ & $170.3(4.0-410.2)$ & NS \\
\hline IL-6 (pg/ml) & $47.65(2.46-1722.62)$ & $41.18(3.57-820.67)$ & $54.98(2.46-1722.62)$ & 0.05 \\
\hline TNF- $\alpha(\mathrm{pg} / \mathrm{ml})$ & $14.82(1.99-181.68)$ & $8.67(1.99-154.14)$ & $25.32(7.29-181.68)$ & 0.004 \\
\hline
\end{tabular}

ICU - intensive care unit, NRS 2002 - nutritional risk screening, PhA - phase angle, $R$ - resistance, Xc - reactance, BCM - body cell mass, MM - muscle mass, $F M$-fat mass, FFM - fat-free mass, TBV-total body water, ECW-extracellular water, ExECW-excess of extracellular water, ICW - intracellular water, BMI - body mass index, TSF - triceps skin fold thickness, MAC - midarm circumference, CRP - C-reactive protein. 
Table 2. Primer sequences and appropriate annealing temperatures used during real-time polymerase chain reaction

\begin{tabular}{lccc}
\hline Gene & Forward sequence & Reverse sequence & Annealing temperatures \\
\hline TLR2 & 5'-TCCATCCCATGTGCGTGGCC-3' & 5'-CAGGACCCCCGTGAGCAGGAT-3' & $59^{\circ} \mathrm{C}$ \\
\hline NOD1 & 5'-GCCCCGCGTTCAGGTCGAAA-3' & 5'-GTGAGGCGGCTGAAGCAGGG-3' & $61^{\circ} \mathrm{C}$ \\
\hline TRAF6 & 5'-AGGGACCCAGCTTTCTTTGTGTGC-3' & 5'-CCGTGCGTGGCAGTTCCACC-3' & $62^{\circ} \mathrm{C}$ \\
\hline HMGB1 & 5'-GGCAAGTGAGAGCCGGACG-3' & 5'-GCTTCTTCTTATGCTCCTCCCGACA-3' & $62^{\circ} \mathrm{C}$ \\
\hline GAPDH & 5'-GTGAAGCAGGCGTCGGAGGG-3' & 5'-GCTCTTGCTGGGGCTGGTGG-3' & $59^{\circ} \mathrm{C}, 61^{\circ} \mathrm{C}$, and $62^{\circ} \mathrm{C}$ \\
\hline
\end{tabular}

in the tested group as multiples of the control group expression.

\section{Ethics}

The study protocol was approved by the Medical University Ethics Committee and conforms to the ethical guidelines of the World Medical Association Declaration of Helsinki.

\section{Statistical analysis}

Statistical analysis was performed using Statsoft Statistica v.13.3 software. The Kolmogorov-Smirnov test was used to investigate the distribution of data. Mann-Whitney $\mathrm{U}$ Test was used to evaluate the statistical significance between gene expression, variables of nutritional status, cytokine concentrations, and age in the tested groups of patients who survived or were deceased. Data are presented as the values of medians and ranges (min-max). The correlations of nutrition status and genetic parameters were calculated with a Spearman's rho test. Differences at $p<0.05$ were considered to be statistically significant.

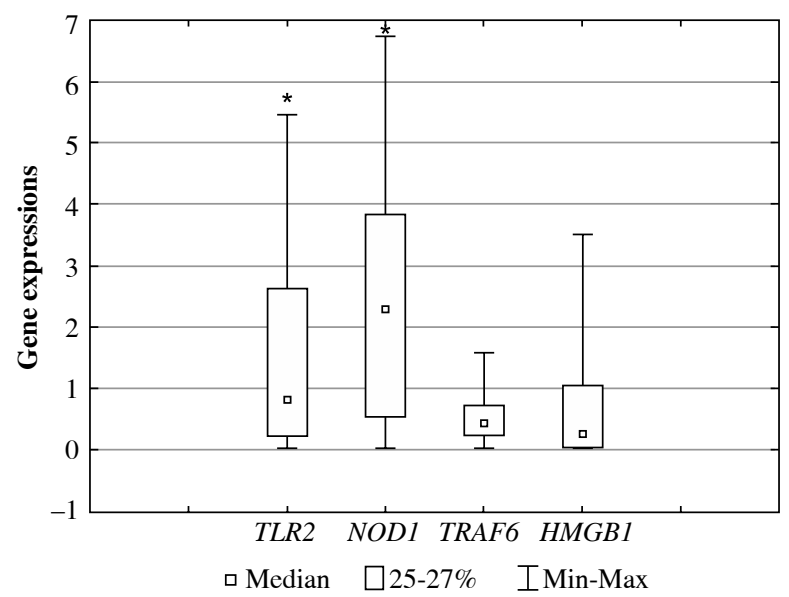

Fig. 1. Gene expressions in critically ill patients with high risk of occurrence malnutrition-related complications (NRS 2002 score 5; APACHE II score 25) tested in the entire group of patients $(n=46$, including survivals and non-survival) on admission to the intensive care unit $\left({ }^{*} p<0.05\right.$, significant upregulation of TLR2 and NOD1 mRNA in comparison with TRAF6 and HMGB1 expression)

\section{Results}

\section{Assessment of nutritional status}

Selected parameters of nutritional status and laboratory tests on critically ill patients measured at admission to the ICU, as well as changes of nutritional status in patients who survived or died in ICU, are presented in Table 1. Patients with a high risk of occurrence of malnutrition-related complications (NRS 2002 scoring 5) were found in the group of patients. The highest NRS 2002 score were recorded in the group of deceased patients.

Body weight did not differ significantly between survivors compared to the deceased (median $83.2 \mathrm{~kg}$, range $54-140.6$ vs. $73 \mathrm{~kg}$, range 50-100). The values of BMI $(p=0.01)$ and triceps skinfold (TSF) $(p=0.01)$ were significantly higher in the group of patients who survived compared to those who died. The age of patients who died was significantly higher compared to survivors (median age 66.6, range $40-87$ vs. 56.0, range $23-86, p=0.003$ ). Cytokine tested in the same groups showed the highest levels in the group of deceased, including only TNF- $\alpha$ plasma concentration $(p=0.004)$ and IL-6 $(p=0.05)$. Compared to the norm, cytokine plasma concentrations in tested groups were significantly increased ( $p<0.05$ for all groups). Body composition measurements showed no difference in $\mathrm{PhA}$ between survivors compared with the deceased, but in $11 / 73 \%$ of patients who died, $\mathrm{PhA}$ values were on average 5.65 degrees. Compared with those patients who died in the ICU, survivors had significantly higher R, Xc, and FM and significantly lower excess of ExECW.

\section{Gene expression and correlations with nutrition status}

The highest expression was found for the NOD1 gene, which was more than twice the norm, and the lowest was found for the TRAF6 and HMGB1 genes. The expression of the TLR2 and NOD1 genes exceeded the expression of the TRAF6 and HMGB 1 genes ( $p<0.05$ for all values) (Fig. 1). In survivors, NOD1 expression was highest compared to the norm and significantly elevated in comparison with TRAF6 $(p=0.001)$ and HMGB1 $(p=0.0006)$. TLR2 expression did not differ from the normal level and was higher only when compared to the values of HMGB1 $(p=0.042)$. Similar changes in gene expression were 
found in the group of deceased patients $(p<0.05$ for all genes), but TRAF6 expression exceeded HMGB1 $(p=0.006)$. Of all the proteins examined, only the HMGB1 gene expression was lower $(p=0.04)$ in deceased patients, compared to survivors (Fig. 2).

In the entire group of patients, the NRS 2002 score values negatively correlated with the expression of the HMGB1 gene $(r=-0.615 ; p=0.00001)$ and with the expression of the TLR2 gene $(r=-0.404 ; p=0.005)$ and the TRAF6 gene $(r=-0.314 ; p=0.03)$ (Fig. 3A-3C). Expression of the HMGB1 gene also correlated with the age of patients $(r=-0.420 ; p=0.003)$ and the ExECW content $(r=-0.336 ; p=0.02)$. In addition, a significant correlation was noted between TLR2 gene expression and body composition results in BI measurement, including: $\mathrm{R}$ $(r=0.389 ; p=0.007), \mathrm{Xc}(r=0.365 ; p=0.01), \mathrm{TBW}$ $(r=-0.323 ; p=0.02)$, and $\mathrm{ECW}(r=-0.353 ; p=0.01)$ (Fig. 3D). Expression of the TRAF6 gene significantly correlated with APACHEII scores $(r=-0.334 ; p=0.02)$.

In ICU patients who survived, the NRS 2002 score values significantly correlated with TLR2 gene expression $(r=-0.538 ; p=0.001)$, HMGB1 $(r=-0.554 ; p=0.001)$,
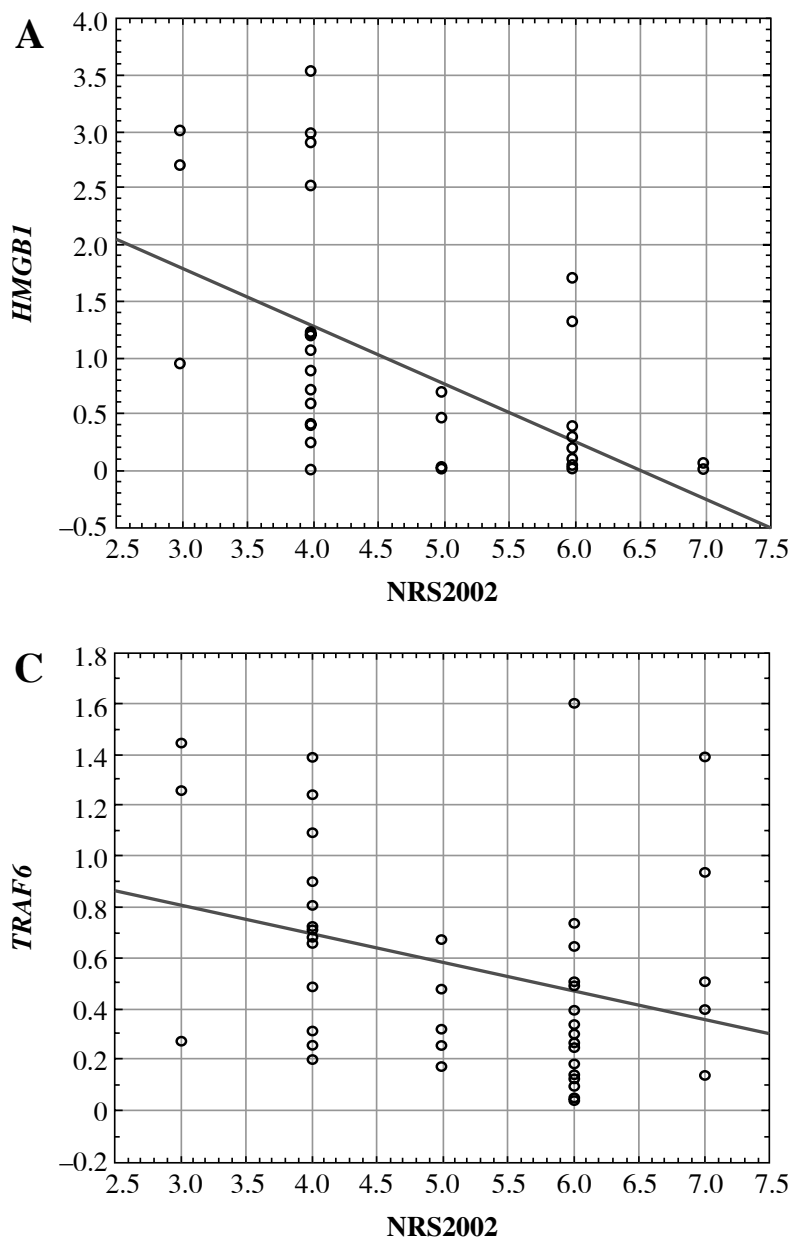

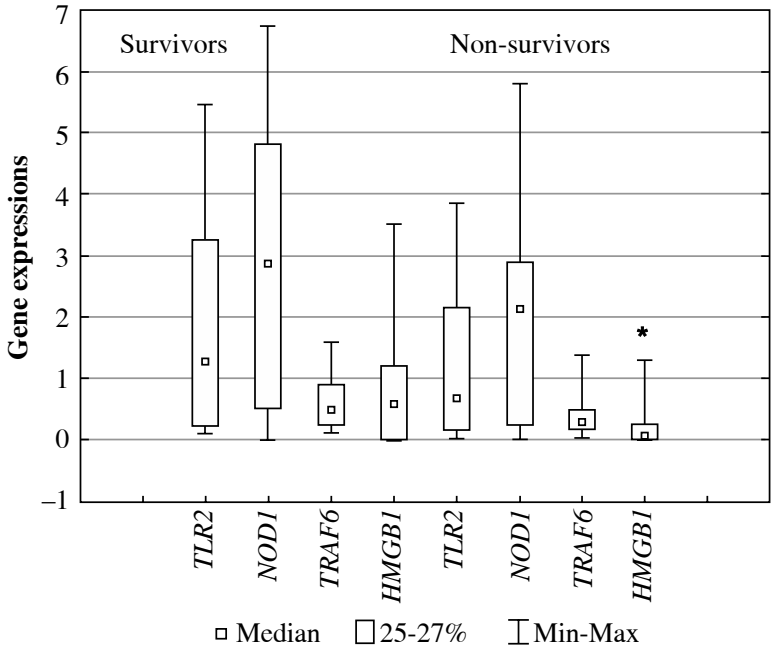

Fig. 2. Gene expressions in critically ill patients who survived (NRS 2002 score 4) compared to the group of deceased patients (NRS 2002 score 6) tested on admission to the intensive care unit $(* p<0.05$, only the $H M G B 1$ gene expression was lower in deceased patients)
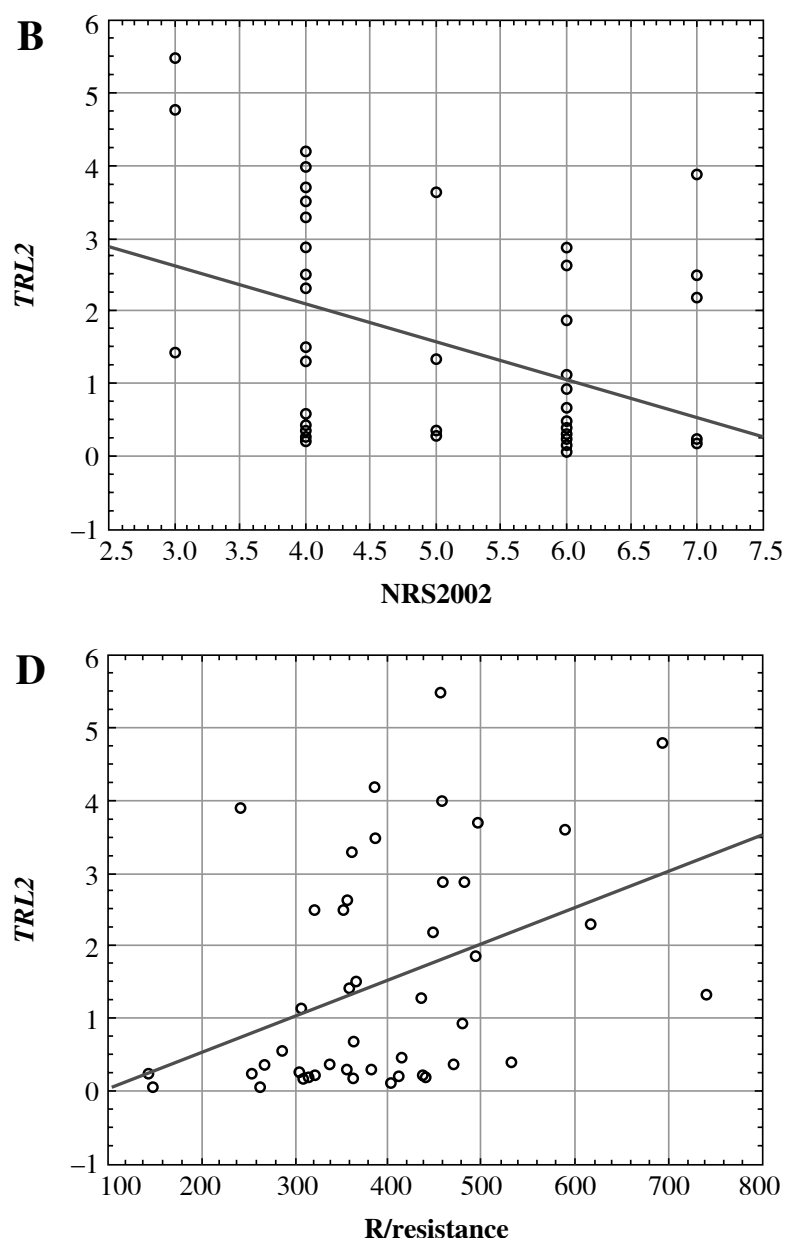

Fig. 3. Correlations between nutritional status disorders (NRS 2002 score and R/resistance) and expression of genes encoding HMGB1, TLR2 and TRAF6 proteins of the innate antibacterial response assessed in the entire group of patients with severe malnutrition on admission to the intensive care unit 
and TRAF6 $(r=-0.361 ; p=0.04)$. A significant correlation was also found in this group of patients between TLR2 gene expression and $\mathrm{R}(r=0.413 ; p=0.02)$ and between HMGB 1 gene expression and albumin concentration $(r=0.461 ; p=0.02)$. In addition, expression of TRAF6 and HMGB1 genes correlated with APACHEII scale values $(r=-0.416 ; p=0.01$ and $r=-0.442, p=0.01$, respectively). Only in the group of survivors was a correlation found between the expression of TLR2 and HMGB1 genes $(r=0.393, p=0.028)$.

In patients from the ICU who died within the first 7 days of admission the results of the nutritional status examined using the NRS 2002 score significantly correlated $(r=0.665, p=0.006)$ with the expression of the TRAF6 gene. A significant correlation was also found between $\mathrm{PhA}$ and BCM values and NOD1 gene expression $(r=-0.542$, $p=0.03$ and $r=0.550, p=0.03$, respectively). Expression of the TRAF6 gene also significantly correlated $(r=0.537$, $p=0.03$ ) with the age of non-survivors.

\section{Discussion}

In analysing the results of the presented research, it should be emphasised that the heterogeneity of the studied groups of patients is of fundamental importance. The nutritional status disorders and changes in the expression of genes of the innate antibacterial response, tested in parallel, may reflect the effects of numerous factors, including underlying diseases, the extent of surgery, severity of complications, and therapeutic management. Despite these factors in our investigations, the most important feature connecting the whole group of patients admitted to the ICU was disease-related malnutrition with varying degrees of severity, which can be called a "separate disease entity". This indicated the need for a more accurate assessment of nutritional status disorders based also on BI analysis and cytokine levels. Taking into account the limited effectiveness of nutritional treatment for some patients with various phases following infection/stress/injury (e.g. acute early, late period or chronic phase/PICS), we extended the assessment of immunity changes associated with malnutrition to include genetic tests. Due to the lack of similar studies in the available literature, especially in ICU patients, the results of our previous studies conducted in a similar patient population (196 patients in total) were a reliable reference point for the currently presented results [38, 39].

The results of the nutritional status assessment by using simple tools confirm their limited usefulness in individual groups of ICU patients, including survivors compared to deceased patients. However, the NRS 2002 score, BMI, TSF, selected BI parameters, and cytokine concentration significantly differentiated study groups on admission to the ICU. Among the routine parameters of nutritional status disorders, which are not often used in ICUs, the results of changes in body composition and cytokine levels deserve particular attention.

Bioelectrical impedance assessment of nutritional status in critically ill patients indicates that $\mathrm{R}$ of body tissues depending on the conduction of body fluids, electrolyte concentration, and capacitive $\mathrm{R}$ of cell membranes (reactance/Xc) varies significantly depending on the severity of the condition and the nutritional status of the examined patients. The results of our studies showed that BI assessment of nutritional status is very useful in patients with severe malnutrition and at high risk of the occurrence of malnutrition-related complications (NRS 2002 score $>5.0$ ), and it should be performed within the first hours after admission to ICU. In ICU malnourished patients, a decrease in the $\mathrm{R}$ of body tissues to the current flowing through them may indicate fluid overload and damage to cell membranes, which can lead to severe complications increasing mortality. An example would be changes in the $\mathrm{BI}$ study in non-survivors with a reduction in $\mathrm{R}$ and $\mathrm{Xc}$ and an accompanying decrease in body fat mass, together with an increase in ExECW. The inverse relationship can be found in the survivors among ICU patients, including those with lower NRS 20002 scores and/or higher BMI and TSF values, which indicate a significantly lower degree of severe malnutrition. Results of BI measurement confirm the well-known usefulness of the applied method (MF-BIA) in the assessment of nutrition, especially in hydration status disorders in ICU patients, as well as indicating the need for its wider use in monitoring the treatment of these patients. Previous analysis of our raw impedance data in larger groups and the impedance vector ( $\mathrm{R} / \mathrm{Xc}$ relationship) compared to confidence limits (tolerance ellipses) designated for a healthy population performed in critically ill patients at ICU admission indicated that approximately $49 \%$ of septic cases exceeded the 50th percentile. These patients were situated in the lower left side of the tolerance ellipses, indicating their overhydration, and the mortality rate in this group was the highest [39]. Several studies have demonstrated a positive correlation between fluid overload and adverse outcomes in critically ill patients, leading to severe complications like pulmonary oedema, cardiac failure, delayed wound healing, tissue breakdown, impaired bowel function, and increased mortality in such patients [48-50].

The levels of pro-inflammatory cytokines changed depending on the examined group of patients. Despite severe malnutrition, a high activity level of immune cells in response to surgical trauma and complications was still preserved. Persistently elevated leukocyte (e.g. neutrophils) activity is an important factor in maintaining overwhelming inflammation, increasing infection complications and the risk of organ failure. This may have been associated with the lower sensitivity of some innate immune cells to apoptosis (e.g. immature neutrophils) [51]. Prolonged neutrophil lifespan at sites of inflammation with liberation of 
bactericidal proteins, release of cytokines and reactive oxygen species are advantageous in clearing bacterial infection but also cause tissue damage (e.g. endothelial injury in acute respiratory distress syndrome, with the mortality rate still approximately 40\%) [52]. Particularly worrying are the highest levels of TNF- $\alpha$ in the group of patients who have died, compared to survivors from ICUs. Perhaps it was an ineffective immune response in malnourished patients, but it also means that in some critically ill patients one of the (molecular/nutritional) therapy targets should be TNF. Recent meta-analyses revealed that in patients with severe sepsis (but before shock), immunotherapy with anti-TNF- $\alpha$ monoclonal antibodies reduces overall mortality, and in patients with shock or high levels of IL-6 $(>1000 \mathrm{pg} / \mathrm{ml})$, anti-TNF- $\alpha$ therapy may improve survival $[53,54]$. It can be assumed that in malnourished patients from ICUs monoclonal antibodies treatment with simultaneous nutritional support (before the onset of immune paralysis) containing elevated concentrations of omega-3 and glutamine can help to down-regulate the expression of TLRs and will have a significant impact on the expression of signalling pathway proteins and the activation of NF- $\kappa \mathrm{B}$ factor and relevant genes, and thus on the production of proinflammatory cytokines (TNF- $\alpha$, IL-6, and IL-1) [26, $32]$. However, further clinical trials are required to establish whether this therapeutic interaction is possible.

The selective upregulation of TLR2 and NOD1 (nucleotide-binding oligomerisation domain 1 protein) mRNA in all groups of malnourished patients from ICUs (including survivals and non-survival) indicate that extensive surgical trauma with infectious complications stimulate the innate antibacterial inflammatory response in peripheral blood leukocytes. It may be a defensive reaction conducive to faster restoration of homeostasis and recovery, but it indicates a disorder in gene expression. Disturbances in the expression of the studied genes may result from the changes in the environment of blood leukocytes (e.g. increased levels of cytokines, and ligands of bacterial origin, overhydration, and lack of nutrients). Increased levels of bacterial-derived ligands in peripheral blood may arise from local late-diagnosed or undiagnosed foci of infection and from damage to the intestinal barrier function, among others, caused by increased TNF- $\alpha$ concentrations, fluid overload (discussed above), and late and/or insufficient enteral/parenteral nutrition of these patients (starvation of GALT may increase inflammatory infiltrates in the intestinal mucosa). The influence of varying severity of malnutrition on the expression of TLR2 and NOD1 genes is confirmed by the correlations presented in our studies. As shown by other authors, loss of critical nutrients, including glutamine and glutamate, may affect epithelial barrier function, contributing to the loss of tight junction proteins. In the total parenteral nutrition (TPN) mouse model TNF- $\alpha$ is also shown to be a major mediator of epithelial barrier dysfunction $[55,56]$.
Increasing the expression of the NOD1 and TLR2 genes, encoding proteins of two major groups of PRRs involved in innate recognition of bacteria, indicates both the antimicrobial activity of leukocytes and the interaction (synergism in action) of these genes. In the heterogeneous group of ICU patients, our study results confirmed the relationship between increased mRNA expression for NOD1 and TLR 2 receptors and elevated TNF- $\alpha$ and IL- 6 levels. Interestingly, experimental research has indicated that activation of both TLRs and NOD signalling resulting in an augmented inflammatory response, and the crosstalk between TLRs and NOD, leads to an amplified downstream NF-kB activation with increased nuclear transactivation of p65 at both TNF- $\alpha$ and IL-6 promoters [57]. The authors of these studies have shown that the administration of both TLR and NOD agonists protected mice against polymicrobial sepsis-associated lethality with increased serum levels of inflammatory cytokines and accelerated clearance of bacteria from the circulation and visceral organs. In another recent study, other authors indicate that synergistic combinations of relatively small doses of NOD and TLR agonists administered before infection could be used to boost innate resistance against bacterial pathogens [58].

In the presented research results, a characteristic element of the innate antibacterial response is the repeated increased expression of NOD1 genes in all groups. In critically ill patients, the increased expression of NOD1 mRNA compared to the expression of the TRAF6 mRNA (tumour necrosis factor receptor-associated factor 6), which is an important signalling pathway adaptor protein associated with the TLRs activation, may be a protective phenomenon. These receptors have the ability to bind lipopolysaccharide (LPS) and bacterial peptidoglycan as well as to transfer a signal independently of TLRs, which also results in NF- $\kappa \mathrm{B}$ activation and stimulation of the expression of cytokine-coding genes (for NOD1: TNF- $\alpha$ and IL-6) [59]. It should be remembered that NOD1 and NOD2 activation can lead to autophagy induction to clear a bacterial threat $[60,61]$. However, this mechanism can also lead to cell death (by apoptosis) in cases of persistent malnutrition and the absence of certain nutrients. The downregulation of TRAF6 mRNA expression was found in all groups of patients. TRAF6 exhibits various functions in regulating adaptive and innate immunity and cell apoptosis, and TRAF6 knockdown promotes cell survival and inhibits inflammatory response to LPS in rats [62]. The impact of severe malnutrition on the expression of the TRAF6 gene is clearly visible in the group of survivors and the deceased, in whom the NRS 2002 score and the age of patients correlated with TRAF6 mRNA. Weakening the immunologic response dependent on TLR2 and TRAF6 gene while maintaining NOD1 expressions may be one of the mechanisms for the adaptation of the innate antimicrobial response to declining nutritional status and immunosuppression. In patients with postoperative com- 
plications, down-regulation of the TLR2-related response may be caused by prolonged LPS-stimulation, which may also induce tolerance to the compound of gram-positive and gram-negative bacteria [63]. Also, mortality in human sepsis is associated with down-regulation of TLR2 receptor expression on blood monocytes [64]. Further research is needed to answer the question of whether nutritional treatment will be able to reverse or inhibit these phenomena. As a result of progressive disturbances in nutritional status, there is also a complete loss of correlation between TLR2 gene expression and NRS 2002 score or R value in deceased patients, which was preserved across the entire group of critically ill and survivors. This may indicate a high sensitivity of TLR2 mRNA expression to severe malnutrition (NRS 2002 score $>6$ ). The problem of the sensitivity of the examined receptors' mRNA to malnutrition remains to be clarified. Perhaps intracellular NOD1 receptors are more resistant to a lack of nutrients, which could be associated with higher gene activity encoding these receptors. In our studies, this may be indicated by the correlation between the elevated expression of NOD1 mRNA and the values of PhA and BCM only in the group of the deceased with the highest degree of malnutrition and highest age.

The smallest differences in gene expression were found between groups of patients who survived and died in the ICU. The differences concerned only a significantly lower expression of mRNA for high mobility group box-1 protein (HMGB1) in the ICU non-survival group. One of the factors responsible for the lowest expression of this gene in the group of deceased patients could be the highest level of severe malnutrition (NRS 2002 score > 6) in these patients as compared to patients from this ward who survived. The influence of severe malnutrition on the expression of HMGB1 mRNA is also confirmed by the correlation of this gene with the NRS 2002 score, excess of ExECW, and with albumin concentration in the entire group of patients and in survivors. The reduced expression of HMGB1 suggests depletion of the intracellular "pool" of this protein both in the cytoplasmic and nuclear regions due to a lack of nutrients. Reduced expression of HMGB 1 mRNA in deceased ICU patients with severe malnutrition and septic complications indicates a worsening of immunosuppression and depletion of protein and energy resources, which was also suggested by our earlier studies [38]. The lack of HMGB1 protein may affect the transcriptional regulation of certain genes. HMGB1 is an important protein binding to DNA and involved in DNA recombination, repair, replication, stabilizing nucleosomes and facilitating NF- $\mathrm{KB}$ activation and gene transcription $[65,66]$. In the presented research, expression of TLR2 mRNA correlated with the expression of HMGB1 mRNA, which may indicate a regulatory relationship for improving the recovery of immune homeostasis. Other factors that reduce HMGB1 mRNA expression in critically ill patients may include an increased immunosuppressive function of the immature myeloid cells (MDSCs/immunosuppressive neutrophils), regulatory T cells (Tregs), and B cells (Bregs). Immunosuppression favours the development of secondary infections and long-term immune disabilities accounting for late mortality [67]. Blocking HMGB1 may be a promising therapeutic intervention to diminish adverse effects of sepsis-induced immunosuppression [68].

In studies on the correlation between the assessed parameters of nutritional status and gene expression, a complex network of the relationships is evident, depending on the group of patients studied. A new look at research results shows that in all patient groups, the correlation between NRS 2002 score and gene expression was most frequently noted, but genes also selectively correlated with body composition measured by BI. The decreased expression of TRAF6 and HMGB1 mRNA correlated with the nutritional status, and with high values of the APACHE II scale and age of patients. Thus, it can be assumed that the deterioration of the nutritional status, the severity of the disease, and the age of the patients may all have a modulating effect on the expression of the studied genes. This means that demonstration of these relationships may have specific therapeutic implications aimed, inter alia, at improving nutritional status and the innate antibacterial response by applying appropriate nutritional therapy.

In summary, the results of the presented studies clearly show a relationship between nutritional status disorders and changes in gene expressions of the innate antibacterial response assessed in patients on admission to the ICU. A correlation was also noted between the results of routine tests used to diagnose malnutrition, severity-of-disease classification, and selected gene expression. Moreover, gene expression and nutritional status changed depending on the group of patients studied (survivors vs. non-survivors). This means that the evaluation of the expression of tested genes may be an additional new diagnostic tool supporting the assessment of nutritional status disorders in ICU patients and should be performed in severely malnourished patients admitted to the ICU. The assessment of the genetic effects of malnutrition and surgical complications should primarily concern patients who are scheduled to undergo intensive immunomodulatory nutritional treatment (e.g. immunonutrition). It is believed that the proposed simple genetic tests (RT-PCR) will be helpful in both patient monitoring and in increasing the effectiveness of nutritional therapy modulating the expression of genes of the innate antibacterial response.

\section{Acknowledgments}

This study was supported by the National Science Centre (NCN Poland, grant no. NN401 103340). We would like to express our special gratitude for support in execution of the research to Mrs. Maria Kopacz. 
The authors declare no conflict of interest.

\section{References}

1. Quenot JP, Binquet C, Kara F, et al. (2013): The epidemiology of septic shock in French intensive care units: the prospective multicentre cohort EPISS study. Crit Care 17: R65.

2. Singer M, Inada-Kim M, Shankar-Hari M (2019) Sepsis hysteria: excess hype and unrealistic expectations. Lancet 394: 1513-1514.

3. Shankar-Hari M, Harrison DA, Rubenfeld GD, et al. (2017): Epidemiology of sepsis and septic shock in critical care units: comparison between sepsis-2 and sepsis-3 populations using a national critical care database. Br J Anaesth 119: 626-636.

4. Sakr Y, Jaschinski U, Wittebole X, et al. (2018): Sepsis in intensive care unit patients: Worldwide Data From the Intensive Care over Nations Audit. Open Forum Infect Dis 5: ofy313.

5. Giner M, Laviano A, Meguid MM, et al. (1996): In 1995 a correlation between malnutrition and poor outcome in critically ill patients still exists. Nutrition 12: 23-29.

6. Lew CCH, Wong GJY, Cheung KP, et al. (2018): Association between malnutrition and 28-day mortality and intensive care length-of-stay in the critically ill: a prospective cohort study. Nutrients 10: 10 .

7. Mogensen KM, Horkan CM, Purtle SW, et al. (2018): Malnutrition, critical illness survivors and post-discharge outcomes: a cohort study. JPEN J Parenter Enteral Nutr 42: 557-565.

8. Delano MJ, Ward PA (2016): The immune system's role in sepsis progression, resolution and long-term outcome. Immunol Rev 274: 330-353.

9. Horiguchi H, Loftus TJ, Hawkins RB, et al. (2018): Innate immunity in the persistent inflammation, immunosuppression, and catabolism syndrome and its implications for therapy. Front Immunol 9: 595.

10. Orban JC, Walrave Y, Mongardon N, et al. (2017): Causes and characteristics of death in intensive care units a prospective multicenter study. Anesthesiology 126: 882-889.

11. Lew CCH, Yandell R, Fraser RJL, et al. (2017): Association between malnutrition and clinical outcomes in the intensive care unit: a systematic review. JPEN J Parenter Enteral Nutr 41: 744-758.

12. Havens JM, Columbus AB, Seshadri AJ, et al. (2018): Malnutrition at intensive care unit admission predicts mortality in emergency general surgery patients. JPEN 42:156-163.

13. Gentile LF, Cuenca AG, Philip A, et al. (2012): Persistent inflammation and immunosuppression: a common syndrome and new horizon for surgical intensive care. J Trauma Acute Care Surg 72: 1491-1501.

14. Moore FA, Phillips S, McClain C, et al. (2017): Nutrition support for persistent inflammation, immunosuppression, and catabolism syndrome. Nutr Clin Pract 32: 121S-127S.

15. Efron PA, Mohr AM, Bihorac A, et al. (2018): Persistent inflammation, immunosuppression, and catabolism and the development of chronic critical illness after surgery. Surgery 164: 178-184.

16. McClave SA, Taylor BE, Martindale RG, et al. (2016): Guidelines for the provision and assessment of nutrition support therapy in the adult critically ill patient: society of Critical Care Medicine (SCCM) and American Society for Parenteral and Enteral Nutrition (A.S.P.E.N.). JPEN J Parenter Enteral Nutr 40: 159-211.
17. Heyland D, Muscedere J, Wischmeyer PE, et al. (2013): A randomized trial of glutamine and antioxidants in Critically Ill Patients. N Engl J Med 368:1489-1497.

18. Singer P, Blaser AR, Berger MM, et al. (2019): ESPEN guideline on clinical nutrition in the intensive care unit. Clin Nutr 38: 48-79.

19. Rosenthal MD, Rosenthal C, Patel J, et al. (2016): Arginine in the Critically Ill: can we finally push past the controversy? Int J Crit Care Emerg Med 2: 017.

20. De Waele E, Malbrain MLNG, Spapen H (2020): Nutrition in sepsis: a bench-to-bedside review. Nutrients 12: 395 .

21. Calder PC, Adolf M, Deutzd NE, et al. (2018): Lipids in the intensive care unit: recommendations from the ESPEN Expert Group. Clin Nutr 37: 1-18.

22. Rhodes A, Evans LE, Alhazzani W, et al. (2017): Surviving sepsis campaign: international guidelines for management of sepsis and septic shock: 2016. Crit Care Med 45: 486-552.

23. Yu L, Wang L, Chen S (2010): Endogenous Toll-like receptor ligands and their biological significance. J Cell Mol Med 14: 2592-2603.

24. Takeuchi O, Akira S (2010): Pattern recognition receptors and inflammation. Cell 140: 805-820.

25. Foley NM, Wang J, Redmond HP, et al. (2015): Current knowledge and future directions of TLR and NOD signaling in sepsis. Mil Med Res 2: 1.

26. Słotwiński R, Słotwińska S, Kędziora S, et al. (2011): Innate immunity signaling pathways: links between immunonutrition and responses to sepsis. Arch Immunol Ther Exp 59: 139-150.

27. Tsujimoto H, Ono S, Efron P, et al. (2008): Role of Toll-like receptors in the development of sepsis. Shock 29: 315-321.

28. Bakopoulos A, Kapelouzou A, Tsilimigras DI, et al. (2017): Expression of Toll-like receptors (TLRs) in the lungs of an experimental sepsis mouse model. PLoS One 12: e0188050.

29. Vidal-Casariego A, Calleja-Fernández A, Villar-Taibo R, et al. (2014): Efficacy of arginine-enriched enteral formulas in the reduction of surgical complications in head and neck cancer: a systematic review and meta-analysis. Clin Nutr 33: 951-957.

30. Hegazi RA, Paul E, Wischmeyer PE (2011): Clinical review: optimizing enteral nutrition for critically ill patients - a simple data-driven formula. Crit Care 15: 234.

31. Zhu X, Pribis JP, Rodriguez PC, et al. (2014): The central role of arginine catabolism in T-cell dysfunction and increased susceptibility to infection after physical injury. Ann Surg 259:171-178.

32. Kessel A, Toubi E, Pavlotzky E, et al. (2007): Treatment with glutamine is associated with down-regulation of Toll-like receptor- 4 and myeloid differentiation factor 88 expression and decrease in intestinal mucosal injury caused by lipopolysaccharide endotoxemia in a rat. Clin Exp Immunol 151: 341-347.

33. Abreu MT, Vora P, Faure E, et al.(2001): Decreased expression of Toll-like receptor-4 and MD-2 correlates with intestinal epithelial cell protection against dysregulated proinflammatory gene expression in response to bacterial lipopolysaccharide. J Immunol 167: 1609-1616.

34. Kędziora S, Słotwiński R, Dąbrowska A, et al. (2012):Glutamine abolishes the TLR-4 gene expression levels in pancreatic cancer patients: a preliminary study. Centr Eur J Immunol 37: 350-354.

35. Gao W, Xiong Y, Li Q, et al. (2017): Inhibition of Toll-like receptor signaling as a promising therapy for inflammatory diseases: a journey from molecular to nano therapeutics. Front Physiol 8: 508. 
36. Hernandez A, Patil NK, Stothers CL, et al. (2019): Immunobiology and application of Toll-like receptor 4 agonists to augment host resistance to infection. Pharmacol Res 150: 104502.

37. Fensterheim BA, Young JD, Luan L, et al. (2018): The TLR4 agonist monophosphoryl lipid A drives broad resistance to infection via dynamic reprogramming of macrophage metabolism. J Immunol 200: 3777-3789.

38. Słotwiński R, Sarnecka A, Dąbrowska A, et al. (2015): Innate immunity gene expression changes in critically ill patients with sepsis and disease-related malnutrition. Cent Eur J Immunol 40: 311-324.

39. Słotwiński R, Milewska M, Kosałka K, et al. (2013): Raw impedance data analysis in severe ill patients with sepsis. Fluids 2: $168-170$.

40. Słotwiński R, Dąbrowska A, Lech G, et al. (2014): Gene expression disorders of innate antibacterial signaling pathway in pancreatic cancer patients: implications for leukocyte dysfunction and tumor progression. Cent Eur J Immunol 39: 498-507.

41. Kondrup J, Rasmussen HH, Hamberg O, et al.(2003): ESPEN working group. Nutritional risk screening (NRS 2002): new method based on an analysis of controlled clinical trials. Clin Nutr 22: 321-336.

42. Maciel LRMA, Franzosi OS, Nunes DSL, et all. (2019): Nutritional risk screening 2002 cut-off to identify high-risk is a good predictor of ICU mortality in critically ill patients. Nutr Clin Pract 34:137-141.

43. Bone RC, Balk RA, Cerra FB, et al. (1992): Definitions for sepsis and organ failure and guidelines for the use of innovative therapies in sepsis. The ACCP/SCCM Consensus Conference Committee. American Collage of Chest Physicians/ Society of Critical Care Medicine. Chest 101: 1644-1655.

44. Levy MM, Fink MP, Marshall JC, et al. (2003): 2001 SCCM/ ESICM/ACCP/ ATS/SIS international sepsis definitions conference. Crit Care Med 31: 1250-1256.

45. Dellinger RP, Levy MM, Rhodes A, et al. (2013): Surviving sepsis campaign: international guidelines for management of severe sepsis and septic shock, 2012. Intensive Care Med 39: 165-228.

46. Seymour CW, Liu VX, Iwashyna TJ, et al. (2016): Assessment of clinical criteria for sepsis for the Third International Consensus Definitions for Sepsis and Septic Shock (Sepsis-3). JAMA 315: 762-774.

47. Livak KJ, Schmittgen TD (2001): Analysis of relative gene expression data using real-time quantitative PCR and 2(Delta Delta C (T)) method. Methods 25: 402-408.

48. Malbrain MLNG, Huygh J, Dabrowski W, et al. (2014): The use of bio-electrical impedance analysis (BIA) to guide fluid management, resuscitation and deresuscitation in critically ill patients: a bench-to-bedside review. Anaesthesiol Intensive Ther 46: 381-391.

49. Wang N, Jiang L, Zhu B, et al. (2015): Fluid balance and mortality in critically ill patients with acute kidney injury: a multicenter prospective epidemiological study. Crit Care 19: 371.

50. Granado RC-D, Mehta RL (2016): Fluid overload in the ICU: evaluation and management. BMC Nephrology 17:109.

51. Hotchkiss RS, Monneret G, Payen D, et al. (2013): Immunosuppression in sepsis: a novel understanding of the disorder and a new therapeutic approach. Lancet Infect Dis 13: 260-268.

52. Potey P, Rossi AG, Lucas CL, et al. (2019): Neutrophils in the initiation and resolution of acute pulmonary inflammation: understanding biological function and therapeutic potential. J Pathol 247: 672-685.
53. Qiu P, Cui X, Sun J, et al. (2013): Anti-tumor necrosis factor therapy is associated with improved survival in clinical sepsis trials: A meta-analysis. Crit Care Med 41: 2419-2429.

54. Lv S, Han M, Yi R, et al. (2014): Anti-TNF- $\alpha$ therapy for patients with sepsis: a systematic meta-analysis. IJCP Int J Clin Pract 68: 520-528.

55. Feng Y, Ralls MW, Xiao W, et al. (2012) Loss of enteral nutrition in a mouse model results in intestinal epithelial barrier dysfunction. Ann N Y Acad Sci 1258: 71-77.

56. Feng Y, Teitelbaum DH (2013): Tumour necrosis factor- $\alpha$-induced loss of intestinal barrier

function requires TNFR1 and TNFR2 signaling in a mouse model of total parenteral nutrition. J Physiol 591: 3709-3723.

57. Zhou H, Coveney AP, Wu M, et al. (2019): Activation of both TLR and NOD signaling confers host innate immunity-mediated protection against microbial infection. Front Immunol 9: 3082.

58. Pashenkov MV, Murugina NE, Budikhina AS, et al. (2019): Synergistic interactions between NOD receptors and TLRs: mechanisms and clinical implications. J Leukoc Biol 105: 669-680.

59. Sońdka Z, Tretyn A, Szeliga J, et al. (2006): Involvement of leucine Roch repeats (LRR) domain containing proteins in molecular mechanisms of innate immunity of plants and Animals. Post Biol Kom 33: 635-656.

60. Travassos LH, Carneiro LA, Ramjeet M, et al. (2010). Nod1 and Nod2 direct autophagy by recruiting ATG16L1 to the plasma membrane at the site of bacterial entry. Nat Immunol 11: 55-62.

61. Juárez E, Carranza C, Hernández-Sánchez F, et al. (2014): Nucleotide-oligomerizing domain-1 (NOD1) receptor activation induces pro-inflammatory responses and autophagy in human alveolar macrophages. BMC Pulm Med 14: 152.

62. Liu S, Lutz J, Chang J, at al. (2010): TRAF6 knockdown promotes survival and inhibits inflammatory response to lipopolysaccharides in rat primary renal proximal tubule cells. Acta Physiol (Oxf) 199: 339-346.

63. Wang JH, Doyle M, Manning BJ, et al. (2002): Induction of bacterial lipoprotein tolerance is associated with suppression of Toll-like receptor 2 expression. J Biol Chem 277: 3606836075.

64. Schaaf B, Luitjens K, Goldmann T, et al. (2009): Mortality in human sepsis is associated with downregulation of Toll-like receptor 2 and CD14 expression on blood monocytes. Diagn Pathol 4:12

65. Mandke P, Vasquez KM (2019): Interactions of high mobility group box protein 1 (HMGB1) with nucleic acids: Implications in DNA repair and immune responses. DNA Repair 83: 102701.

66. Bustin M (1999): Regulation of DNA-dependent activities by the functional motifs of the high-mobility-group chromosomal proteins. Mol Cell Biol 19: 5237-5246.

67. Venet F, Monneret G (2018): Advances in the understanding and treatment of sepsis-induced immunosuppression. Nat Rev Nephrol 14: 121-137.

68. Grégoire M, Tadié J-M, Uhel F, et al. (2017): Frontline Science: HMGB1 induces neutrophil dysfunction in experimental sepsis and in patients who survive septic shock. J Leukoc Biol 101: 1281-1287. 